\title{
Lemon protein disulfide isomerase: cDNA cloning and biochemical characterization
}

\author{
Yu-Ting Chen ${ }^{2 \dagger}$, Lisa Wen ${ }^{3+}$, Kuo-Chuan Ho ${ }^{1 \dagger}$, Rong-Huay Juang ${ }^{4+}$ and Chi-Tsai Lin ${ }^{1 *}$
}

\begin{abstract}
Background: Protein disulfide isomerases (PDIs), a family of structurally related enzymes, aid in protein folding by catalyzing disulfide bonds formation, breakage, or isomerization in newly synthesized proteins and thus.

Results: A CIPDI cDNA (1828 bp, GenBank accession HM641784) encoding a putative PDI from Citrus limonum was cloned by polymerase chain reaction (PCR). The DNA sequence encodes a protein of 500 amino acids with a calculated molecular mass of $60.5 \mathrm{kDa}$. The deduced amino acid sequence is conserved among the reported PDIs. A 3-D structural model of the CIPDI has been created based on the known crystal structure of Homo sapiens (PDB ID: 3F8U_A). The enzyme has two putative active sites comprising the redox-active disulfides between residues 60-63 and 405-408 (motif CGHC). To further characterize the CIPDI, the coding region was subcloned into an expression vector pET-20b (+), transformed into E. coli Rosetta (DE3)pLysS, and recombinant protein expressed. The recombinant CIPDI was purified by a nickel Sepharose column. PDI's activity was assayed based on the ability of the enzyme to isomerize scrambled RNase A (sRNase A) to active enzyme. The $K_{M}, k_{\text {cat }}$ and $k_{\text {cat }} / K_{M}$ values were $8.3 \times$ $10^{-3} \mu \mathrm{M}, 3.0 \times 10^{-5} \mathrm{~min}^{-1}$, and $3.6 \times 10^{-1} \mathrm{~min}^{-1} \mathrm{mM}^{-1}$. The enzyme was most active at $\mathrm{pH} 8$.
\end{abstract}

Conclusions: The advantage of this enzyme over the PDI from all other sources is its low $K_{M}$. The potential applications of this PDI in health and beauty may worth pursuing.

Keywords: Citrus limonum; Protein disulfide isomerase (PDI); Scrambled RNase A (sRNase A); Three-dimension structural model (3-D structural model)

\section{Background}

Protein disulfide isomerase (PDI), a member of thioredoxinsuperfamily, plays a key role in catalyzing disulfide bond formation, reduction, and isomerization. It was the first reported protein folding enzyme (Venetianer and Straub 1963a, 1963b; Goldberger et al. 1963). PDI is best known as resided in endoplasmic reticulum (ER) where folding, modification, and quality control of many secretory and cellsurface proteins take place (Hatahet and Ruddock 2009; Lambert and Freedman 1983). In vivo, native disulfide bond formation involves the formation of new disulfides (oxidation) and the rearrangement of non-native disulfides (isomerization). PDI, contains combinations of catalytically active and inactive thioredoxin domains, is capable of catalyzing

\footnotetext{
* Correspondence: B0220@mail.ntou.edu.tw

${ }^{\dagger}$ Equal contributors

${ }^{1}$ Institute of Bioscience and Biotechnology and Center of Excellence for the Oceans, National Taiwan Ocean University, 2 Pei-Ning Rd, Keelung 202,

Taiwan

Full list of author information is available at the end of the article
}

both the oxidation of new disulfides and the isomerization of existing disulfides (Kulp et al. 2006). The first and last domains (referred to as a and a' domain, respectively) contain CxxC active site motifs, whereas the two middle domains (referred to as b and b' domain) are catalytically inactive (Kemmink et al. 1997). Oxidation, catalyzed by the a' domain, involves the transfer of an active site disulfide from PDI to substrate proteins. Isomerization, catalyzed by the a domain, requires the active site cysteines to be in the reduced form in order to attack non-native disulfides in substrate proteins thereby catalyzing their rearrangement (Kulp et al. 2006).

Like other proteins with thioredoxin folds, PDI is a multifunctional protein (Pedone et al. 2010). In addition to catalyze protein folding, PDI is the $\beta$-subunit of prolyl-4-hydroxylase (Koivu et al. 1987), is a subunit of microsomal triglyceride transfer protein (Wetterau et al. 1991), acts as a chaperone (Wang and Tsou 1993), is implicated in peptide loading onto MHC class I (Peaper and Cresswell 2008), and is involved in regulating $\mathrm{NAD}(\mathrm{P}) \mathrm{H}$ oxidase (Janiszewski

\section{空}


et al. 2005). Although members of PDI enzyme have a classic 'KDEL' ER retention signal at the C-terminal end (Pelham 1990), the enzymes have been identified outside the ER at many subcellular locations and are known to involve in a wide range of biological functions (Turano et al. 2002). Outside of ER, PDI has been reported to serve as switches for modulating protein function in some cases (Hogg 2003; Wouters et al. 2010). For instance, extracellular PDI mediated disulfide exchange has been shown to switch tissue factor between coagulation to cell signaling (Wouters et al. 2010; Ahamed et al. 2006).

Lemon is an economically valuable produce in Taiwan. It is an amazing fruit that has been used as natural remedy for health and beauty. PDI has been used as an ingredient in cosmetic agents for treating hair (European Patent WO2003099243 A1). Here, we report the cloning of a putative PDI cDNA from lemon, namely ClPDI. The coding region of the CIPDI cDNA was introduced into an $E$. coli expression system and the active enzyme purified and characterized. Understanding the properties of this CIPDI will be beneficial for its potential applications such as catalyzing protein folding or serving a chaperone contributing to reactivation of inactive enzymes.

\section{Methods}

\section{Total RNA preparation from lemon and cDNA synthesis}

A fresh lemon (Citrus limonum) was obtained from a local market. The lemon including the skin $(4 \mathrm{~g})$ was frozen in liquid nitrogen and ground to powder in a ceramic mortar. PolyA mRNA $(35 \mu \mathrm{g})$ was prepared using Straight A's mRNA Isolation System (Novagen, USA). Four $\mu \mathrm{g}$ of the mRNA was used in the $5^{\prime}$-RACE-Ready cDNA and 3'-RACE-Ready cDNA synthesis using Clontech's SMART RACE cDNA Amplification Kit.

\section{Isolation of CIPDI CDNA}

Using the 5 '-RACE-Ready cDNA of lemon as a template and two degenerate primers (5' AGY CAA GGT GCH TTC CAG 3' and ACY TTM ACW GGC TCR TTG $\mathrm{TT}$ ), a $0.2 \mathrm{~kb}$ fragment was amplified by PCR. The degenerate primers were designed based on the conserved sequences of PDI from AtPDI (Arabidopsis thaliana, AY063059), HsPDI (Homo sapiens, 3F8U_A), MmPDI (Mus musculus, 2DJ2_A), HiPDI (Humicola insolens, 2DJJ_A). The $0.2 \mathrm{~kb}$ fragment was subcloned and sequenced. On the basis of this DNA sequence, two primers near both ends, a ClPDI-6R primer (5' ACY TTM ACW GGC TCR TTG TT 3') and a ClPDI-7 F primer (5' GCA CCT TGG GTG AAG GAA TAC 3') were synthesized. The primers allowed sequence extension from both ends of the $0.2 \mathrm{~kb}$ fragment when used with the UPM primer (universal primer A mix, purchased from BD biosciences). Two PCRs were carried out each using $0.1 \mu \mathrm{g}$ of the $5^{\prime}$-RACE-Ready cDNA or 3 '-RACE-Ready cDNA as a template. The primer pairs in each reaction were UPM and CIPDI-6R primers, and UPM and ClPDI-7 F primers. A $1.3 \mathrm{~kb}$ fragment $\left(5^{\prime}-\right.$ RACE; 5' -DNA end) and a $1.0 \mathrm{~kb}$ DNA (3'-RACE; 3'DNA end) were amplified by PCR. Both DNA fragments were subcloned into pCR4 vector and transformed into E. coli TOPO10. The nucleotide sequences of these inserts were determined in both strands. Sequence analysis revealed that the combined sequences covered an open reading frame of a putative CIPDI cDNA (1828 bp, EMBL no. HM641784). The identity of this ClPDI clone was assigned by comparing the inferred amino acid sequence in various data banks using the basic local alignment search tool (BLAST).

\section{Bioinformatics analysis of CIPDI}

The BLASTP program was used to search homologous protein sequences in the nonredundant database (NRDB) at the National Center for Biotechnology Information, National Institutes of Health (http://www.ncbi.nlm.nih.gov/). Multiple alignments were constructed using ClustalW2 program. Protein secondary structure was predicted by SWISSMODEL program and represented as $\alpha$ helices and $\beta$ strands. A 3-D structural model of PDI was created by SWISS-MODEL (http://swissmodel.expasy.org/) based on the known crystal structure of Homo sapiens PDI (PDB code 3F8U_A) (Dong et al. 2009). The modeling data was then superimposed with that of PDB ID: 3F8U_A by DeepView Swiss-PdbViewer v4.1 (http://spdbv.vital-it.ch/).

\section{Subcloning of CIPDI CDNA into an expression vector}

The coding region of the CIPDI cDNA was amplified using gene specific flanking primers. The $5^{\prime}$ upstream primer contains EcoRI recognition site (5' CGT CTC GAA TTC GAT GGC CAG TCG ATC GAT 3') and the 3' downstream primer contains Not I recognition site (5' GCG GCC GCG AGC TCA TCT TTT CCA GA 3'). Using $0.2 \mu \mathrm{g}$ of CIPDI cDNA as a template, and 10 pmole of each 5 ' upstream and 3 ' downstream primer, a $1.5 \mathrm{~kb}$ fragment was amplified by PCR. The fragment was ligated into pCR4 and transformed into E. coli. The recombinant plasmid was isolated and double digested with EcoRI and Not I. The digestion products were separated on a $1.0 \%$ agarose gel. The $1.5 \mathrm{~kb}$ fragment was gel purified and subcloned into the EcoRI and Not I site of pET-20b(+) expression vector (Novagen). The recombinant DNA was then transformed into $E$. coli Rosetta (DE3)pLysS and protein expressed by isopropyl $\beta$-D-thiogalactopyranoside (IPTG) induction. Expression of functional recombinant protein was demonstrated by enzyme activity assay as described below. 
Expression and purification of the recombinant CIPDI

The transformed E. coli containing the ClPDI gene was grown at $37^{\circ} \mathrm{C}$ in $200 \mathrm{~mL}$ of Luria-Bertani containing $50 \mu \mathrm{g} / \mathrm{mL}$ ampicillin until $A_{600}$ reached 0.6. Protein expression was induced by the addition of IPTG to a final concentration of $50 \mu \mathrm{M}$. The culture was incubated at $80 \mathrm{rpm}$ for an additional $2 \mathrm{~h}$ at $32^{\circ} \mathrm{C}$. The cells were harvested and soluble proteins extracted in PBS with glass beads as described before (Ken et al. 2005). The recombinant ClPDI was purified by Ni-NTA affinity chromatography (elution buffer: $30 \%$ PBS containing $20-250 \mathrm{mM}$ imidazole) as per the manufacture's instruction (Qiagen). The purified protein was checked by a $10 \%$ SDS-PAGE. Protein bands on gel were visualized by staining with Coomassie Brilliant Blue R-250. Protein concentration was determined by a Bio-Rad Protein Assay Kit (Richmond, CA) using bovine serum albumin as a reference standard.

\section{Molecular mass analysis via electrospray ionization quadrupole-time-of-flight (ESI Q-TOF)}

The purified recombinant ClPDI $(0.21 \mathrm{mg} / \mathrm{mL})$ was prepared in $0.1 \mathrm{mM}$ Tris- $\mathrm{HCl}$ containing $0.05 \mathrm{mM} \mathrm{NaCl}$, $0.5 \mathrm{mM}$ imidazole and $0.03 \%$ glycerol. The sample $(5 \mu \mathrm{L})$ was used for molecular mass determination using an ESI Q-TOF mass spectrometer (Micromass, Manchester, England).

\section{CIPDI activity assay}

PDI activity was assayed by the method of Ibbetson and Freedman (1976) using scrambled ribonuclease (sRNase A) as a substrate. In this method, PDI was used to activate sRNase A then the ribonuclease activity was monitored spectrophotometriclly as described below. Each $5 \mu \mathrm{L}$ CIPDI sample $(0.2 \mu \mathrm{g} / \mu \mathrm{L}$ stock solution) was first pre-incubated with $10 \mu \mathrm{L}$ of $100 \mu \mathrm{M}$ DTT (dithiothreitol) for $5 \mathrm{~min}$ at $25^{\circ} \mathrm{C}$. Next, a $0-60 \mu \mathrm{L}$ portion of the sRNase A $(0.036 \mu \mathrm{M})$ was added, followed by addition of $10 \mu \mathrm{L}$ of $0.5 \mathrm{M}$ Tris/ $\mathrm{HCl}, \mathrm{pH} 7.5$ and appropriate amount of $\mathrm{H}_{2} \mathrm{O}$ to $90 \mu \mathrm{L}$. The mixture was incubated for $20 \mathrm{~min}$ at $25^{\circ} \mathrm{C}$ to allow conversion of sRNase A to active RNase by PDI. The RNase activity was then measured by its ability to degrade RNA. Ten $\mu \mathrm{L}$ of RNA $(2 \mu \mathrm{g} / \mu \mathrm{L})$ was added to each assay mixture (Total volume was $100 \mu \mathrm{L}$ ). The samples were incubated at $37^{\circ} \mathrm{C}$ for another $5 \mathrm{~min}$. Three hundred $\mu \mathrm{L}$ of $95 \%$ ethanol was added to each assay mixture to precipitate the residual RNA. Ribonuclease activity was monitored by observing the decrease in $A_{260}$ of the residual RNA.

\section{Kinetic studies}

The kinetic properties of the CIPDI $(1.0 \mu \mathrm{g})$ was determined by varying the concentrations of sRNase A ( 3.6 to $21.6 \mathrm{nM}$ ) with fixed amount of $20 \mu \mathrm{g}$ RNA $(2 \mu \mathrm{g} / \mu \mathrm{L})$. The change in absorbance at $260 \mathrm{~nm}$ was recorded between 1 and $20 \mathrm{~min}$.
The $K_{\mathrm{M}}, \mathrm{V}_{\max }$ and $k_{\text {cat }}$ were calculated from LineweaverBurk plots.

\section{Enzyme characterization}

The CIPDI enzyme was tested for stability in terms of its activity under various conditions. Aliquots of the CIPDI sample $(1.0 \mu \mathrm{g})$ were treated as follows: (1) Thermal effect. Each enzyme sample $(1.0 \mu \mathrm{g})$ was heated at $37,50,60,70$, or $80^{\circ} \mathrm{C}$ for $20 \mathrm{~min}$. (2) pH effect. Each enzyme sample $(1.0 \mu \mathrm{g})$ was adjusted to desired $\mathrm{pH}$ by adding a half volume of buffer

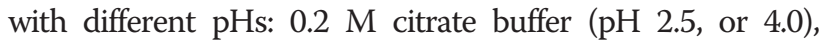
$0.2 \mathrm{M}$ phosphate buffer (pH 6.0, 7.0 or 8.0) or 0.2 M CAPS buffer ( $\mathrm{pH} 10.0$, or 11.0). Each sample was incubated at $37^{\circ} \mathrm{C}$ for $1 \mathrm{~h}$. (3) Imidazole effect. During protein purification, the CIPDI enzyme was eluted with imidazole, therefore, its effect on activity was examined. Imidazole was added to each enzyme sample to the final levels of $0.2,0.4$, 0.8 or $1.0 \mathrm{M}$ and incubated at $37^{\circ} \mathrm{C}$ for $1 \mathrm{~h}$. (4) DTT effect. DTT was added to each enzyme sample to the final levels of $10,30,70,100$ or $200 \mu \mathrm{M}$ and incubated at $37^{\circ} \mathrm{C}$ for $5 \mathrm{~min}$. At the end of each treatment, samples were checked for CIPDI activity.

\section{Results and discussion}

Cloning and characterization of a CDNA encoding CIPDI

A putative CIPDI CDNA clone was identified on the basis of the consensus pattern and sequence homology to other published PDIs in NCBI database. The entire coding region of CIPDI cDNA is $1503 \mathrm{bp}$ and the deduced protein consists of 500 amino acid residues with a calculated molecular mass of $60.5 \mathrm{kDa}$ (Accession no. HM641784). Figure 1 shows the optimal alignment of the amino acid sequences of the CIPDI with 3 selected CIPDI sequences from other sources. This ClPDI shared $70 \%$ identity with AtPDI (Arabidopsis thaliana, AY063059), 35\% with HsERp57 (Homo sapiens, NP_005304, 3F8U_A), and 37\% with HiPDI (Humicola insolens, AAC60578, 2DJJ_A). The two highly conserved catalytic motifs are denoted in red boxes $\left(\mathrm{C}^{60} \mathrm{GHC}^{63}, \mathrm{C}^{405} \mathrm{GHC}^{408}\right.$, Figure $\left.1 \mathrm{~A}\right)$ located in the two putative catalytic domains, a and a'. The secondary structure, predicted by SWISS-MODEL program, showed 14 $\alpha$ helices and $19 \beta$ strands. The structure of PDI is currently recognized as having four distinct domains, a, b, b', and a' (as marked in Figure 1A), plus a highly acidic C-terminal extension (which contains the ER-localization motif: KDEL) and an interdomain linker between the b' and a' domains (Hatahet and Ruddock 2009; Wang et al. 2010). The 3-D structural model was superimposed with PDB ID: 3F8U_A (orange) via the SPDBV_4 program was shown using protein solid ribbon (Figure 1B).

\section{Expression and purification of the recombinant CIPDI}

The coding region of the CIPDI (1503 bp) was amplified by PCR and subcloned into an expression vector, pET- 


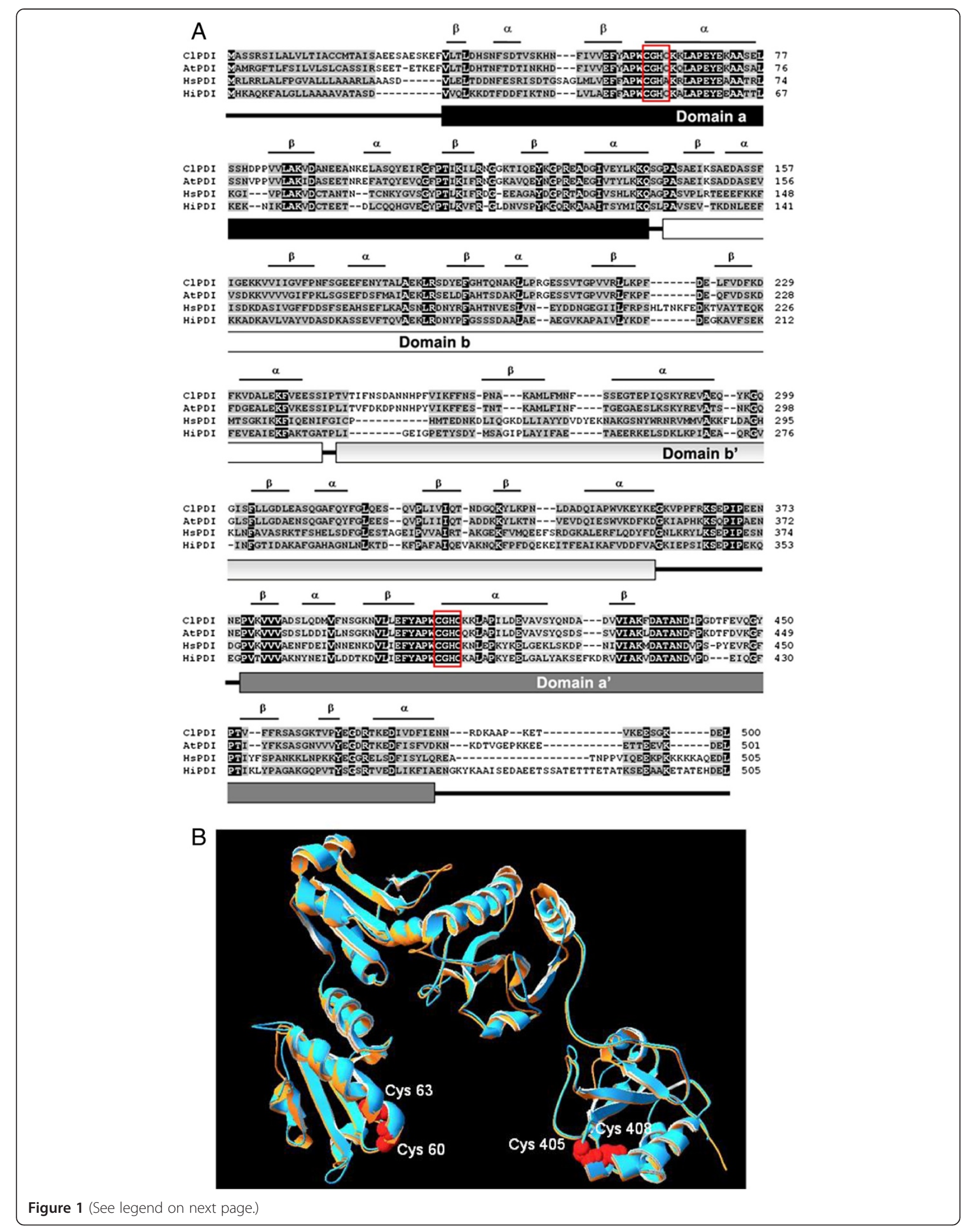


(See figure on previous page.)

Figure 1 Alignment of the amino acid sequences of CIPDI with other organism's PDI and 3-D structural model. (A) Sequence alignment: CIPDI (this study), AtPDI (Arabidopsis thaliana, AY063059), HsPDI (Homo sapiens, P30101), HiPDI (Humicola insolens, AAC60578). Identical amino acids in all sequences are shaded black, conservative replacements are shaded gray. Two red boxes denote highly conserved catalytic motifs $\left(\mathrm{C}^{60} \mathrm{GHC}^{63}, \mathrm{C}^{405} \mathrm{GHC}^{408}\right)$. Protein secondary structure was predicted by SWISS-MODEL program and represented as a helices and $\beta$ strands. Underline shows the positions of the domains corresponding to domains $a, b, b^{\prime}$ and $a^{\prime}$. (B) A 3-D structural model of CIPDI. The structural model of the CIPDI was created based on the known crystal structure of Homo sapiens PDI (PDB: 3F8U_A) via SWISS-MODEL program and was superimposed with PDB ID: 3F8U_A (orange) to obtain structure alignment via SPDBV_4 program.

20b (+) as described in the Materials and Methods. Positive clones were verified by DNA sequence analysis. The recombinant CIPDI was expressed, and the proteins were analyzed by a $10 \%$ SDS-PAGE in the absence of reducing agent and without boiling (Figure 2). The recombinant CIPDI was not expressed in the absence of IPTG (data not shown). In the presence of IPTG, it was expressed as a $\mathrm{His}_{6}$-tagged fusion protein and was purified by affinity chromatography with nickel chelating Sepharose. A major band of $\sim 63 \mathrm{kDa}$ (expected size of recombinant CIDPI monomer) was detected in Ni-NTA eluted fractions by SDS-PAGE (Figure 2, lanes 5-7). The fractions contained pure protein were pooled and characterized further. Analysis of the CIPDI by ESI Q-TOF confirms the presence of a single protein with molecular mass of $60.5 \mathrm{kDa}$. This indicates that the enzyme is predominantly monomeric in nature. The yield of the purified $\mathrm{His}_{6}$-tagged CIPDI was $875 \mu \mathrm{g}$ from $100 \mathrm{~mL}$ of culture. Functional CIPDI was detected by activity assay as describe below.

\section{Kinetic studies of the purified CIPDI}

The purified recombinant CIPDI possesses PDI activity as demonstrated by its ability to activate sRNase A through oxidation and shuffling of disulfide bonds.

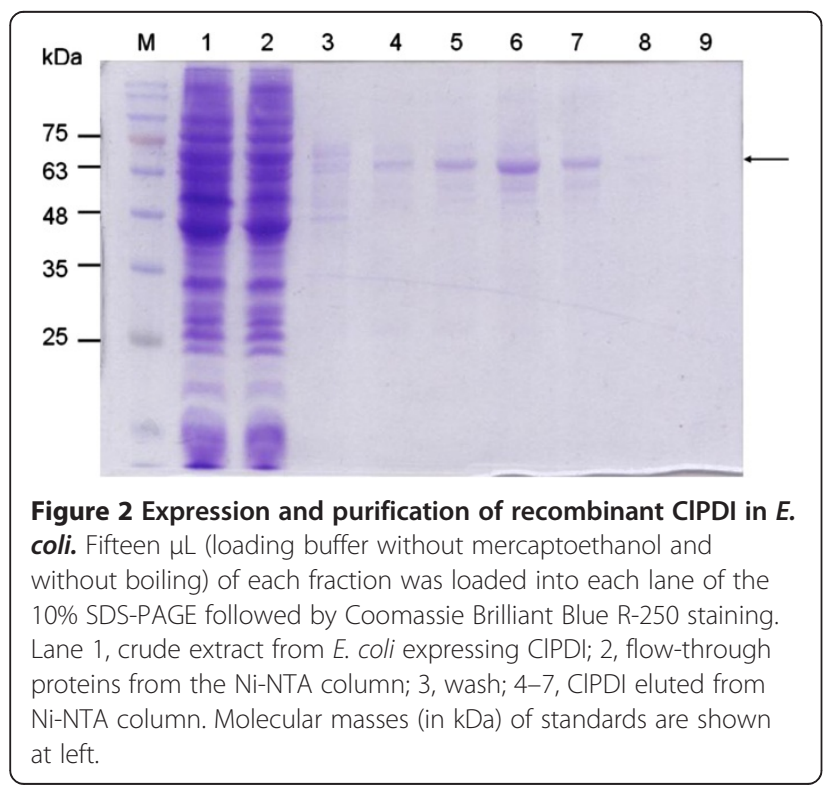

Kinetic study of the CIPDI was done by varying substrate concentration of sRNase A. As shown in Figure 3, the Lineweaver-Burk plot of the velocity $(1 / \mathrm{V})$ against $1 /$ sRNAase A gave the $K_{\mathrm{M}}, k_{\text {cat }}$ and $k_{\text {cat }} / K_{\mathrm{M}}$ values were $8.3 \times 10^{-3} \mu \mathrm{M}, 3.0 \times 10^{-5} \mathrm{~min}^{-1}, 3.6 \times 10^{-1} \mathrm{~min}^{-1} \mathrm{mM}^{-1}$. Comparison of the $K_{\mathrm{M}}$ with that of PDI from other available sources (Table 1) reveals that lemon's $K_{\mathrm{M}}$ is several orders of magnitude smaller. The result indicating that the CIPDI can work under extremely low substrate concentration. The wide variation of $K_{\mathrm{M}}$ values among the reported data may due to differences in reaction conditions and whether the redox buffer was sufficiently reducing to maintain PDI in an active form. According to Lambert and Freedman (1983) that the bovine liver PDI requires the presence of either a dithiol or a thiol. Dithiothreitol is effective at concentrations 100fold lower than that of monothiols such as reduced glutathione or cysteamine. The enzyme follows Michaelis-Menten kinetics with respect to these substrates; $K_{\mathrm{M}}$ values were 4, 620 in the presence of reduced glutathione and $380 \mu \mathrm{M}$ in the presence of DTT. This is one reason to say why animal's (bovine, and rat) $K_{\mathrm{M}}$ values (8 to $380 \mu \mathrm{M})$ vary so widely. This reason was also supported by Lyles and Gilbert (1991) that the rat PDI's catalysis depends on the composition of the redox

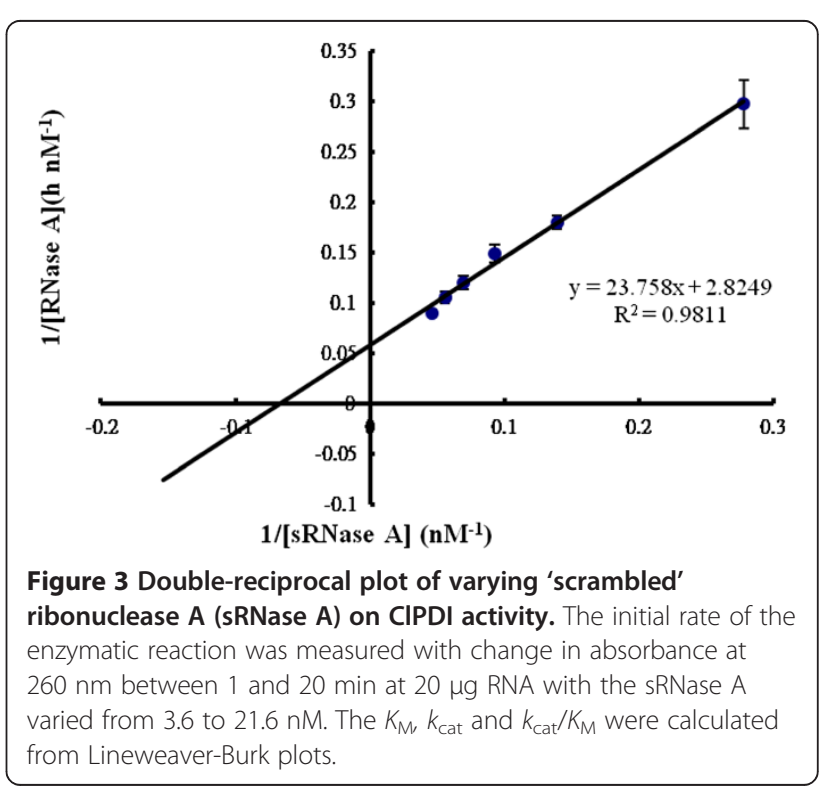


Table 1 Kinetic characterization of CIPDI and that from other sources

\begin{tabular}{lllll}
\hline Species & \multicolumn{1}{c}{$\boldsymbol{K}_{\mathbf{M}}$} & \multicolumn{1}{c}{$\begin{array}{c}\boldsymbol{k}_{\text {cat }} \\
(\boldsymbol{\mu} \mathbf{m})\end{array}$} & $\begin{array}{c}\boldsymbol{k}_{\text {cat }} / \boldsymbol{K}_{\mathbf{M}} \\
\left(\mathbf{m i n}^{-1} \mathbf{~ m M}^{-1}\right)\end{array}$ & Ref. \\
\hline Lemon & $8.3 \times 10^{-3}$ & $3.0 \times 10^{-5}$ & $3.6 \times 10^{-1}$ & This study \\
Human* & $0.21 \sim 2$ & $0.21 \sim 0.89$ & $1 \sim 0.44$ & Westphal et al. 1998 \\
Bovine & $8.0 \pm 1.5$ & $0.46 \pm 0.05$ & $5.58 \times 10^{-2}$ & Lyles and Gilbert 1991 \\
Bovine & 380 & $\mathrm{NA}$ & $\mathrm{NA}$ & Lambert and Freedman 1983 \\
Rat & $67 \pm 7$ & $1.3 \pm 0.1$ & $1.94 \times 10^{-2}$ & Walker and Gilbert 1997
\end{tabular}

Values for PDI are from this work (lemon) or from the literatures (human, bovine, and rat ).

*Human PDI was assayed using fluorescence-quenched peptides as substrate instead of sRNase A.

buffer. The human PDI was assayed using fluorescencequenched peptides as substrate instead of sRNase A. Therefore, a direct comparison cannot be made.

The $k_{\text {cat }}$ value of CIPDI is also several orders of magnitude smaller than that of PDI from other sources (Table 1 ). But its $k_{\text {cat }} / K_{\mathrm{M}}$ value is compatible to that of PDI from other sources. It is likely that the CIPDI is one of the early enzymes that responsible for oxidative folding of proteins in lemon as the enzyme can respond to extremely low substrate concentration.

\section{Characterization of the purified CIPDI}

The stability of the enzyme activity was characterized under various conditions. As shown in Figure 4A, thermal stability of the CIPDI was tested to examine the effect of heat on the PDI activity. The purified CIPDI was heat-treated as described in the Materials and Methods and then analyzed for the residue PDI activity. A control reaction where the enzyme was treated at $25^{\circ} \mathrm{C}$ was counted as $100 \%$ activity. The enzyme activity decreased as the temperature increased. There was only $8 \%$

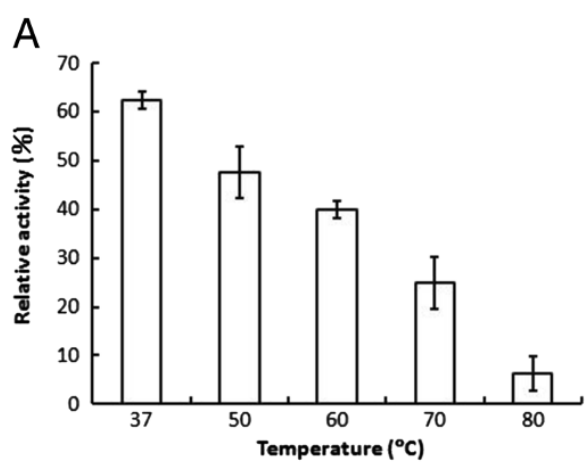

B
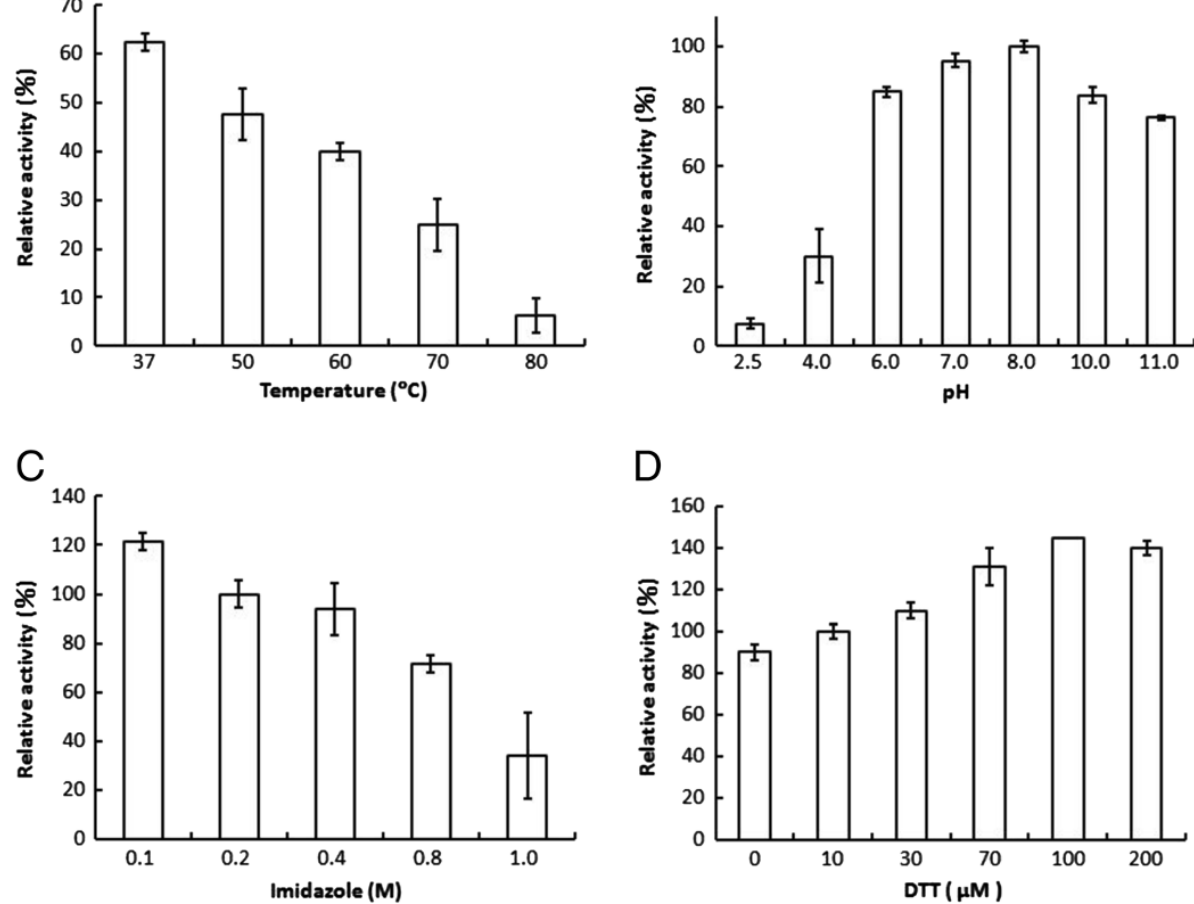

D

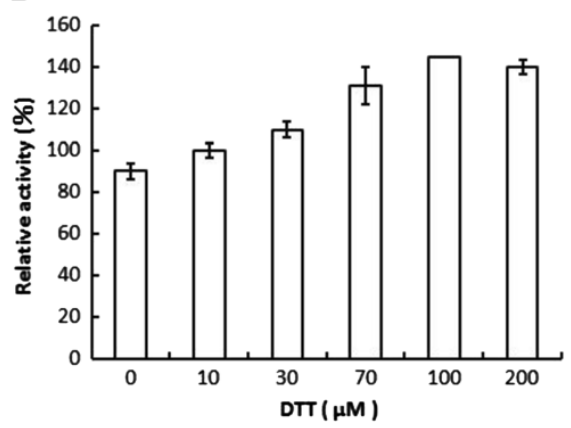

Figure 4 Effect of temperature, pH, imidazole, and DTT on the purified CIPDI. The enzyme sample (1.0 $\mu \mathrm{g})$ was heated at 37, 50, 60, 70, or $80^{\circ} \mathrm{C}$ for $20 \mathrm{~min}$. At the end of each treatment, samples were assayed for CIPDI activity at pH 7.5 (A). Aliqouts of the enzyme sample were incubated with different $\mathrm{pH}$ buffers at $37^{\circ} \mathrm{C}$ for $1 \mathrm{~h}$ and then assayed for CIPDI activity (B). Imidazole was added to each enzyme sample $(1.0 \mathrm{\mu g})$ to the final levels of $0.2,0.4,0.8$ or $1.0 \mathrm{M}$ and incubated at $37^{\circ} \mathrm{C}$ for $1 \mathrm{~h}$ and then assayed for CIPDI activity at pH 7.5 (C). DTT was added to each enzyme sample $(1.0 \mu \mathrm{g})$ to the final levels of $10,30,70,100$ or $200 \mu \mathrm{M}$ and incubated at $37^{\circ} \mathrm{C}$ for $5 \mathrm{~min}$ and then assayed for CIPDI activity at pH 7.5 (D). Data are means of three experiments. 
detectable activity when the enzyme was heated at $80^{\circ} \mathrm{C}$ for $20 \mathrm{~min}$. In Figure 4B, the CIPDI is activity under a broad $\mathrm{pH}$ range from 6-11 with an optimal activity at $\mathrm{pH}$ 8.0. The enzyme retained $30 \%$ activity at $\mathrm{pH} 4.0$. The enzyme showed a decrease in its activity with increasing imidazole concentration from 0.2-1 M (Figure 4C). Approximately $70 \%$ activity was lost in the presence of $1 \mathrm{M}$ imidazole. The enzyme activity was enhanced in the presence of thiol reducing agent (DTT), the ClPDI activity was correlated with the increasing concentration of DTT from 10 to $100 \mu \mathrm{M}$ (Figure 4D) and it reached the plateau at approximately $100 \mu \mathrm{M}$.

\section{Conclusion}

The importance of PDI has been implicated in health and disease (Benham 2012; Andreu et al. 2012). This study reported the first cloning and expression of an important protein folding enzyme, ClPDI, from lemon. The active form of the ClPDI has been successfully expressed in $E$. coli and characterized. The advantage of this enzyme over the PDI from all other sources is its extremely low $K_{\mathrm{M}}$. The potential applications of this enzyme in health and beauty may worth pursuing.

\section{Abbreviations \\ PDI: Protein disulfide isomerase; sRNase A: Scrambled RNase A; IPTG: Isopropyl $\beta$-D-thiogalactopyranoside; SDS-PAGE: Sodium dodecyl sulfate-polyacrylamide gel electrophoresis; PBS: Phosphate buffer saline.}

\section{Competing interest}

The authors declare that they have no competing interests.

\section{Authors' contributions}

Y-TC and K-CH carried out the molecular genetic studies and biochemical studies. C-TL was an adviser to carry out the molecular genetic and biochemical studies. LW and R-HJ participated in drafting the manuscript. C-TL and LW drafted the manuscript and revised the manuscript. All authors read and approved the final manuscript.

\section{Acknowledgements}

This work was supported by the National Science Council of the Republic of China, Taiwan under grant NSC 100-2313-B-019-003-MY3 to C-T. Lin.

\section{Author details}

${ }^{1}$ Institute of Bioscience and Biotechnology and Center of Excellence for the Oceans, National Taiwan Ocean University, 2 Pei-Ning Rd, Keelung 202,

Taiwan. Institute of Genomics and Bioinformatics, Agricultural Biotechnology Center, National Chung Hsing University, Taichung, Taiwan. ${ }^{3}$ Department of Chemistry, Western Illinois University, 1 University Circle, Macomb, IL 61455-1390, USA. ${ }^{4}$ Department of Biochemical Science and Technology, National Taiwan University, Taipei 106, Taiwan.

Received: 27 May 2013 Accepted: 12 September 2013 Published: 16 September 2013

\section{References}

Ahamed J, Versteeg HH, Kerver M, Chen VM, Mueller BM, Hogg PJ, Ruf W (2006) Disulfide isomerization switches tissue factor from coagulation to cell signaling. Proc Natl Acad Sci USA 103:13932-13937

Andreu Cl, Woehlbier U, Torres M, Hetz C (2012) Protein disulfide isomerases in neurodegeneration: from disease mechanisms to biomedical applications. FEBS Lett 586:2826-2834

Benham AM (2012) The protein disulfide isomerase family: key players in health and disease. Antioxid Redox Signal 16:781-789
Dong G, Wearsch PA, Peaper DR, Cresswell P, d Reinisch KM (2009) Insights into MHC class I peptide loading from the structure of the tapasin/ERp57 heterodimer. Immunity 30:21-32

Goldberger RF, Epstein CJ, Anfinsen CB (1963) Acceleration of reactivation of reduced bovine pancreatic ribonuclease by a microsomal system from rat liver. J Biol Chem 238:628-635

Hatahet F, Ruddock LW (2009) Protein disulfide isomerase: a critical evaluation of its function in disulfide bond formation. Antioxid \& Redox Signaling 11:2807-2850

Hogg PJ (2003) Disulfide bonds as switches for protein function. Trends in Biochem Sci 28:210-214

Ibbetson AL, Freedman RB (1976) Thiol-protein disulphide oxidoreductases. Assay of microsomal membrane-bound glutathione-insulin transhydrogenase and comparison with protein disulphide-isomerase. Biochem J 159:377-384

Janiszewski M, Lopes LR, Carmo AO, Pedro MA, Brandes RP, Santos CXC, Laurindo FRM (2005) Regulation of NAD(P)H oxidase by associated protein disulfide isomerase in vascular smooth muscle cells. J Biol Chem 280:40813-40819

Kemmink J, Darby NJ, Dijkstra K, Nilges M, Creighton TE (1997) The folding catalyst protein disulfide isomerase is constructed of active and inactive thioredoxin modules. Curr Biol 7:239-245

Ken CF, Hsiung TM, Huang ZX, Juang RH, Lin CT (2005) Characterization of Fe/ Mn-superoxide dismutase from diatom Thallassiosira weissflogii: cloning, expression, and property. J Agric Food Chem 53:1470-1474

Koivu J, Myllyla R, Helaakoski T, Pihlajaniemi T, Tasanen K, Kivirikko KI (1987) A single polypeptide acts both as the $\beta$-subunit of prolyl 4-hydroxylase and as a protein disulfide isomerase. J Biol Chem 262:6447-6449

Kulp MS, Frickel EM, Ellgaard L, Weissman JS (2006) Domain architecture of protein-disulfide isomerase facilitates its dual role as an oxidase and an isomerase in Erolp-mediated disulfide formation. J Biol Chem 281:876-884

Lambert N, Freedman RB (1983) Kinetics and specificity of homogeneous protein disulphide-isomerase in protein disulphide isomerization and in thiol-protein -disulphide oxidoreduction. Biochem J 213:235-243

Lyles MM, Gilbert HF (1991) Catalysis of the oxidative folding of ribonuclease A by protein disulfide isomerase: dependence of the rate on the composition of the redox buffer? Biochemistry 30:613-619

Peaper DR, Cresswell P (2008) Regulation of MHC class I assembly and peptide binding. Annu Rev Cell Dev Biol 24:343-368

Pedone E, Limauro D, D'Ambrosio K, De Simone G, Bartolucci S (2010) Multiple catalytically active thioredoxin folds: a winning strategy for many functions. Cell Mol Life Sci 67:3797-3814

Pelham HR (1990) The retention signal for soluble proteins of the endoplasmic reticulum. Trends Biochem Sci 15:483-486

Turano C, Coppari S, Altieri F, Ferraro A (2002) Proteins of the PDI family: unpredicted non-ER locations and functions. J Cell Physiol 193:154-163

Venetianer P, Straub FB (1963a) Enzymic formation of the disulfide bridges of ribonuclease. Acta Physiol Acad Sci Hung 24:41-53

Venetianer P, Straub FB (1963b) The enzymatic reactivation of reduced ribonuclease. Biochim Biophys Acta 67:166-168

Walker KW, Gilbert HF (1997) Scanning and escape during protein-disulfide isomerase assisted protein folding. J Biol Chem 272:8845-8848

Wang CC, Tsou CL (1993) Protein disulfide isomerase is both an enzyme and a chaperone. FASEB J 7:1515-1517

Wang C, Chen S, Wang X, Wang L, Wallis AK, Freedman RB, Wang CC (2010) Plasticity of human protein disulfide isomerase evidence for mobility around the $x$-linker region and its functional significance. J Biol Chem 285:26788-26797

Westphal V, Spetzler JC, Meldal M, Christenseni U, Winther JR (1998) Kinetic analysis of the mechanism and specificity of protein disulfide isomerase using fluorescence-quenched peptides. J Biol Chem 273:24992-24999

Wetterau JR, Combs KA, McLean LR, Spinner SN, Aggerbeck LP (1991) Protein disulfide isomerase appears necessary to maintain the catalytically active structure of the microsomal triglyceride transfer protein. Biochemistry 30:9728-97235

Wouters MA, Fan SW, Haworth NL (2010) Disulfides as redox switches: from molecular mechanisms to functional significance. Antioxid \& Redox Signal 12:53-91

\section{doi:10.1186/1999-3110-54-34}

Cite this article as: Chen et al:: Lemon protein disulfide isomerase: CDNA cloning and biochemical characterization. Botanical Studies 2013 54:34. 